\title{
La unión hace la fuerza
}

Dr. Miguel Á. Ayerza

Presidente de la AAOT

Estimados colegas:

Esta Comisión Directiva que asume la responsabilidad de dirigir nuestra AAOT durante un año, se compromete a afianzar los objetivos fundacionales de mantener nuestro más alto nivel académico en el estudio de las afecciones del aparato locomotor, pero también a estimular la unión profesional entre nuestros socios.

Para ello, durante nuestro último Congreso, hemos mantenido reuniones con los presidentes de todas las Sociedades Integrantes, indagando necesidades básicas, objetivos comunes y conociendo los logros académicos de cada asociación. Fueron dos mañanas de mucho intercambio, donde recibimos reclamos hacia la AAOT, como "el especialista tiene la necesidad de que el NUN esté implementado en todo el país", "descartar de nuestros cursos de instrucción las clases magistrales", "como sociedad integrante, la AAOT nos da poco", "hay congresos de la AAOT con pocos exponentes y no cubren todos los temas", "la AAOT, como sociedad madre, genera poca unión entre nosotros los especialistas".

Asimismo, surgieron observaciones, como "la necesidad de utilizar más seguido el streaming en nuestras actividades académicas", "intensificar la comunicación de las actividades que hace la AAOT" y cumplir el rol de sociedad madre "trabajando en la unión e integración de las sociedades integrantes".

Esta Comisión Directiva pretende, como lo han hecho otras, continuar con el crecimiento científico de la AAOT en forma homogénea y en todo el país. También, con el fin de trabajar en la unión de nuestros especialistas, enviamos una encuesta durante el mes de diciembre, a nuestros 5733 asociados, indagando cuáles son los puntos en común que puedan generar la unión a través de nuestra actividad médica. De las 1084 respuestas recibidas durante las semanas de fin de año, pudimos recabar la siguiente información preliminar:

- El 82\% de nuestros socios considera que es muy importante el logro que la AAOT alcanzó en 2019 al obtener un certificado universitario de especialista en Ortopedia y Traumatología.

- La mayoría considera que la AAOT ofrece importantes beneficios al socio, como la educación médica continuada, el congreso anual, la certificación universitaria y el soporte bibliográfico. Sin embargo, también advierten que la AAOT ofrece poca protección gremial del profesional médico, y como prioridad, no actualiza ni desarrolla el NUN en todo el país con la intensidad esperada.

- El 70\% considera que el avance del NUN a nivel nacional está frenado por la falta de unión de los propios colegas.

- Las vías de comunicación más utilizadas por el socio son la página web de la AAOT (60\%) y las Newsletters con información general de la AAOT y las sociedades integrantes (30\%).

- El $47 \%$ considera que no es miembro titular de la AAOT, porque no tiene disponibilidad de tiempo, mientras que el $20 \%$ tiene dificultades para desarrollar un trabajo científico.

Dr. MIGUEL Á. AYERZA • miguelayerza@gmail.com

Cómo citar este artículo: Ayerza MÁ. La unión hace la fuerza. Rev Asoc Argent Ortop Traumatol 2020;85(1):1-2. https://doi.org/10.15417//issn. 1852-7434.2020.85.1.1048 
La encuesta también incluyó una última pregunta para desarrollar: ¿qué espera usted de la AAOT para el 2020? Las respuestas fueron variadas, pero muchas contenían términos como: "escaso desarrollo de la actividad gremial", "avance del NUN para todos los traumatólogos unidos", "más beneficios para los socios del interior", "austeridad en el manejo de sus fondos".

Recibir estos comentarios nos obliga a cambiar, no solo a estar más alerta en seguir con la excelencia educativa, sino en cubrir también las necesidades del socio: Educación Ortopédica, protección gremial, implementación del NUN en todo el país. Como vemos, nos espera un desafío interesante, pero en un año particular donde muchos traumatólogos necesitamos estar juntos y trabajar intensamente en el desarrollo de la AAOT. Para eso contamos con una comisión directiva joven, pero con experiencia en actividad societaria, diversa al representar distintas provincias del país, pero homogénea como un grupo de amigos unidos por una misma pasión. Contamos además con un personal muy profesional y con mucha experiencia en el manejo de nuestra casa.

Por lo tanto, a todos los socios les queremos decir que estamos listos trabajando en nuestra asociación y les pedimos que participen, que sigan invirtiendo en su conocimiento médico, pero que queremos trabajar más juntos, que pretendemos apostar al futuro generando la unión entre todos nuestros asociados para que nos permita llevar a cabo nuestros intereses comunes. 